\title{
Erken Evre Meme Kanserli Hastalarda Hızlandırılmış Kısmi Meme Işınlamasında VMAT-CyberKnife Sanal Tedavi Planlarının İncelenmesi
}

\author{
Hidayetül Mediha KILIÇ, Sibel KAHRAMAN ÇETINTAŞ, Mehmet TOSUN, \\ Metin ZORLUTUNA, Sema GÖZCÜ TUNÇ, Meral KURT, \\ Candan DEMIRÖZ ABAKAY
}

Bursa Uludağ Üniversitesi Tıp Fakültesi, Radyasyon Onkolojisi Anabilim Dalı, Bursa.

\begin{abstract}
ÖZET
Erken evre meme kanserli hastalarda hızlandırılmış kısmi meme ışınlamasında Volümetrik Ark Terapi (VMAT) ve CyberKnife teknikleri kullanılarak hedef volüm ile kritik organ dozlarının karșılaștııılması amaçlanmıștır. Bu çalıșma için radyoterapi almış 10 erken evre meme kanseri tanılı hasta seçilerek, günlük fraksiyon dozu 6 Gy ve toplam doz 30 Gy olacak şekilde VMAT ve CyberKnife (SBRT) sanal planları olușturuldu. Homojenite indeksi (HI), konformite indeksi (CI), tedavi süresi (s), görünür hedef volümü (GTV) ve kritik organların aldığı doz değerleri karşılaştırıldı. Tedavi planları arasında GTV'nin $\mathrm{D}_{\max }(\mathrm{p}=0,002)$ değeri VMAT tekniği lehine anlamlı fark bulundu. Aynı taraf memenin $30 \mathrm{~Gy}\left(\mathrm{~V}_{30}\right)(\mathrm{p}=0,013)$ ve $15 \mathrm{~Gy}$ alan $\left(\mathrm{V}_{15}\right)$ volüm değerlerinin $(\mathrm{p}=0,007)$ CyberKnife tekniğinde daha az doz aldığı görüldü. Karşı memenin $\mathrm{D}_{\max }(\mathrm{p}=0,218)$ değeri açısından anlamlı bir fark bulunmamıștır. Sağ meme yerleșimli olgularda kalbin $\mathrm{D}_{\max }(\mathrm{p}=0,282)$ ve $1,5 \mathrm{~Gy}$ alan $\left(\mathrm{V}_{1,5}\right)$ volümü için $(\mathrm{p}=0,548)$ anlamlı fark bulunmadı. Sol meme yerleşimli olgularda kalbin $\mathrm{D}_{\max }(\mathrm{p}=0,095)$ değerinde anlamlı fark görülmedi; ancak kalbin 1,5 Gy alan $\left(\mathrm{V}_{1,5}\right)$ volüm değerinin $(\mathrm{p}=0,008)$ CyberKnife tekniğinde daha düșük olduğu görüldü. Tedavi süresi $(\mathrm{s})$ $(\mathrm{p}<0,001)$ VMAT tekniğinde anlamlı olarak az bulunmuştur. Sonuç olarak iki tedavi tekniğinde de hedef volümün istenilen dozu aldığı; ancak özellikle erken evrede oluşabilecek geç kardiyak yan etkilerin azaltılması açısından riskli hastalarda CyberKnife tekniğinin daha üstün olduğu anlaşılmıştır. Teknolojik gelişmeler ışığında erken evre meme kanserli hastalarda Hızlandırılmış Kısmi Meme Işınlamasında (APBI) güncel tedavi yaklaşımı olarak CyberKnife tekniği uygun olgularda değerlendirilebilir.
\end{abstract}

Anahtar Kelimeler: APBI. Erken evre meme kanseri. Volümetrik ark terapi. CyberKnife, SBRT.

Investigation of VMAT-Cyberknife Virtual Treatment Plans in Accelerated Partial Breast Irradiation in Patients with Early Stage Breast Cancer

\begin{abstract}
It is aimed to compare target volume and critical organ doses by using Volumetric Arc Therapy (VMAT) and CyberKnife techniques in accelerated partial breast irradiation in patients with early stage breast cancer. For this study, 10 patients diagnosed with early stage breast cancer who received radiotherapy were selected. VMAT and CyberKnife (SBRT) virtual plans were created with a daily fraction dose of 6 Gy and a total dose of $30 \mathrm{~Gy}$. Homogeneity index (HI), conformity index (CI), treatment duration (s), gross tumor volume (GTV) and dose values received by critical organs were compared. A significant difference was found between the treatment plans in favor of the VMAT technique in the Dmax $(\mathrm{p}=0.002)$ value of GTV. It was observed that $30 \mathrm{~Gy}\left(\mathrm{~V}_{30}\right)(\mathrm{p}=0.013)$ and $15 \mathrm{~Gy}\left(\mathrm{~V}_{15}\right)$ values $(\mathrm{p}=0.007)$ of the ipsilateral breast received less dose in CyberKnife technique. There was no significant difference in terms of Dmax $(\mathrm{p}=0.218)$ of the contralateral breast. No significant difference was found for Dmax $(p=0.282)$ and volume of the heart receiving $1.5 \mathrm{~Gy}\left(\mathrm{~V}_{1.5}\right)(\mathrm{p}=0.548)$ in cases located in the right breast. There was no significant difference in heart Dmax $(\mathrm{p}=0.095)$ in cases located in the left breast; however, the value $(\mathrm{p}=0.008)$ of the heart receiving $1.5 \mathrm{~Gy}\left(\mathrm{~V}_{15}\right)$ was found to be lower in the CyberKnife technique. The duration (s) of treatment $(\mathrm{p}<0.001)$ was found to be significantly less in the VMAT technique. As a result, in both treatment techniques, the target volume received the desired dose; however, it has been found that the CyberKnife technique is superior in risky patients in terms of reducing late cardiac side effects that may occur especially in the early stage. In the light of technological developments, CyberKnife technique can be evaluated in appropriate cases as a current treatment approach in Accelerated Partial Breast Irradiation (APBI) in patients with early stage breast cancer.
\end{abstract}

Key Words: APBI. Early stage breast cancer. Volumetric arc therapy. CyberKnife, SBRT.

Geliş Tarihi: 29.Eylül.2021

Kabul Tarihi: 02.Kasım.2021

Dr. Sibel KAHRAMAN ÇETINTAŞ

Bursa Uludağ Üniversitesi Tıp Fakültesi,

Radyasyon Onkolojisi Anabilim Dalı,

Bursa.

Tel: 05326565474

E-posta: skahraman@uludag.edu.tr
Hidayetül Mediha KILIÇ: 0000-0002-0022-1140

Sibel KAHRAMAN CETINTAS: 0000-0002-4483-9284

Mehmet TOSUN: 0000-0002-8034-2507

Metin ZORLUTUNA: 0000-0001-9445-2208

Sema Gözcü TUNÇ: 0000-0003-4697-8234

Meral KURT: 0000-0003-1637-910X

Candan DEMIRÖZ ABAKAY: 0000-0001-5380-5898 
Meme kanseri dünyada kadınlarda en sık izlenen kanserdir. Kanser sebebiyle oluşan ölümlerde ise akciğer kanserinden sonra ikinci sırada yer almaktadır. Türkiye'de meme kanseri \%23,4 oranıyla kadınlarda görülen kanserler içinde ilk sırada yer almaktadır ${ }^{1}$. Günümüzde gelişmiş ülkelerde erken tarama programları ve halkın bilinçlenmesi ile meme kanserli olgular daha erken evrede tanı almaktadır. Erken evre meme kanseri hastalara normal yaşama şansı vermektedir ${ }^{1}$. Meme kanserinde uygulanan tedavi yöntemleri arasında; cerrahi, radyoterapi, kemoterapi ve hormonal tedavi bulunmaktadır. Hastanın klinik ve patolojik durumuna göre belirtilen tedavi seçeneklerinden biri veya daha fazlasi uygulanmaktadır ${ }^{2}$. Radyasyon tedavisi ile konservatif cerrahi, erken evre meme kanseri için mastektomiye bir alternatif olarak uygulanmaktadır. Erken evre meme kanseri tedavisi, meme koruyucu cerrahi (MKC) ve ardından da tüm meme ışınlaması şeklindedir. Bu tedaviler lokal nüks oranını oldukça azaltır ${ }^{3}$.

Birçok gelişmiş ülkede radyoterapi, meme kanserli hastaların yaklaşık olarak yarısı tarafından tedavi seçeneği olarak ilk sırada gelmektedir. Erken evre meme kanserinde, radyoterapinin ölüm riskini ve kanserin yineleme oranını azalttığ 1 yapılan tedaviler sonucu kanıtlanmıştır ${ }^{4}$. Erken evre meme kanseri için, Uluslararası Standart Radyoterapi rejimi, meme koruyucu cerrahiden sonra 25 fraksiyonda 2 Gy'lik dozdan toplam 50 Gy'lik doz uygulamasıdır. Özellikle radyoterapinin başlamasında sıra bekleme probleminden dolayı tedavide gecikme olması ve uzun süreli tedaviye gelip gitme sebebi ile lokal kontrolü ve sağ kalımı etkilemeden toplam tedavi süresini kısaltmayı amaçlayan çalışmalar başlamıştır. $\mathrm{Bu}$ doz uygulama alternatifi, daha büyük fraksiyonlarda daha düşük bir toplam doz verme şeması olan Hipofraksiyonasyondur. Hipofraksiyon için Kanada ve Birleşik Krallık'ta, genel olarak 3 hafta boyunca 15 fraksiyonda toplam 40 Gy'lik doz reçetesi kullanılmıştır. Erken evre meme kanserinde hipofraksiyon radyoterapinin birtakım retrospektif çalışmaları, tümör kontrolü açısından tatmin edici sonuçlar ortaya koymuştur ${ }^{5-7}$. Hizland1rılmış Kısmi Meme Işınlaması (Accelerated Partial Breast Irradiation, APBI), geleneksel fraksiyonlamadan daha yüksek fraksiyon dozları kullanarak tedavi süresini azaltmayı amaçlayan bir tedavi yöntemi olarak geliştirilmiştir ${ }^{6}$. APBI, tüm meme dokusu yerine yalnızca lumpektomi yatağı ve/veya 1-2 cm'lik marj1 tedavi eder ${ }^{7}$. Tüm meme işınlamasının aksine, burada reçete edilen doz yalnızca rezeksiyon (memenin cerrahi sonucu çıkarılan bölümü) hacmine verilir ${ }^{6}$. APBI'nın tedavi uygulamalarına girişinin ana nedeni, seçilen hasta grubunda meme koruyucu cerrahi (MKC)'den sonra tüm meme ışınlaması ile karşılaştırıldığında tedavinin, daha kısa sürede tamamlanması ve daha az toksisiteye sahipken, eşdeğer lokal kontrol oranlarına ulaşacağı düşüncesidir ${ }^{8}$. Mastektomi geçirmiş olgularda radyoterapiye bağlı oluşabilecek komplikasyon riskini en az seviyeye düşürmek için, risk altındaki organların (örneğin: karşı meme, aynı taraf meme, kalp ve akciğerler) yeterli miktarda korunmaları gerekir'. Radyoterapi sürecinde çevredeki sağlıklı doku ve organların doz alması kaçınılmaz bir durumdur. Bu durumda erken ve geç yan etki görülebilir. Erken yan etkiler radyoterapinin başlangıcı ile ilk 12 hafta içinde gelişen etkilerdir. Bu dönemde meme ödemi, halsizlik, cilt bulguları ve özafajit görülebilir. Geç yan etkiler olan yağ nekrozu, meme dokusundaki kalsifikasyon ve radyasyon pnömonisi ise radyoterapi tamamlandıktan uzun bir süre sonra tüm yaşam süresince azalarak görülebilir ${ }^{10}$.

Radyasyona bağlı kalp hasarının patofizyolojik mekanizmaları tam olarak anlaşılmasada, çoklu etkilerin kalp toksisitesine katkıda bulunduğu bilinmektedir ${ }^{11}$. Radyasyona bağlı kardiyovasküler hastalığın patofizyolojisinde perikardit, perikardiyal fibroz, difüz miyokart fibrozu ve koroner arter hastalığı rol oynar. Radyoterapiye bağlı gelişen perikarditlerin $(\% 0,3)$ çoğu 6 12 ayda görülmektedir ${ }^{12}$. Sol meme radyoterapisinde anatomik yakınlık nedeniyle ortalama kalp dozu yüksektir" . '20 y1llik EBCTGG'nin verilerinin ön analizinde, ortalama kalp dozundaki her 1 Gy'lik artış ile kalp hastalığından ölüm riskinin \%3 oranında arttığ1 bildirilmektedir" "14. Meme kanseri radyoterapisi gören hastalarda kalbin maruz kaldığı radyasyon dozunu azaltabilen ışın açılarının optimizasyonu, çok yapraklı kolimatör (ÇYK) kullanımı, yoğunluk ayarlı radyoterapi (YART), yüzüstü pozisyonda tedavi, proton $1 s ̧ ı n$ tedavisi (PIT), kısmi meme radyasyonu ve derin inspirasyonda tedavi (nefes tutma teknikleri) dahil olmak üzere birçok teknik mevcuttur ${ }^{14}$.

Stereotaktik Beden Radyoterapisi (SBRT), beden içerisinde bulunan tümörlerin üç boyutlu konumland1rılması ilkesine dayandırılan ve bu sebeple daha kısa sürede (1-5 fraksiyon) çok daha yüksek fraksiyon dozlarının hedef hacme verilmesini sağlayan tedavi tekniğidir ${ }^{15-6}$." Erken evre primer ve oligometastatik kanserleri kontrol etmede, abdominopelvik ve torasik boşluklar boyunca ve spinal-paranspinal bölgelerde oldukça etkili olan bir prosedürü ifade eder". SBRT, sağlıklı dokulara ve kritik yapılara dozu azaltarak, doğru tümör lokalizasyonu, görüntü yönlendirme ve hasta immobilizasyonu tekniklerini kullanarak tümör kapsamını yüksek seviyeye çıkararak geleneksel tedavilere göre klinik olarak avantaj sağlamaya çalışır ${ }^{15}$. Meme kanserli hastalarda, tümör yatağında referans işaretleyici kliplerin olması doğru tanımlanmış hedefe SBRT uygulamasını mümkün kılmaktadır ${ }^{16}$. SBRT uygulaması farklı tedavi teknikleri ile yapılabilmektedir. VMAT ve CyberKnife bu tedavi tekniklerinden bazılarıdır.

Volümetrik ayarlı ark terapi (VMAT), farklı yoğunluklardan oluşan 1şın demeti kullanarak ve her 1şın demetinin birbiri içerisinde yoğunluğunu değiştirmesiyle, hedef hacim üzerinde homojen doz dağılımını sağlar. Çok yapraklı kolimatörlerin birbirlerinden bağımsız hızları, gantri dönüş hızı ve doz çıkış hızı değişkenlik göstererek 4 boyutlu (4B) hesaplama 


\section{Erken Evre Meme Kanserinde CyberKnife}

kazanımı sağlar. Değişken doz hızı ile tedavi süresini kısaltmayı amaçlayan böylelikle biyolojik yanıtı artıran radyoterapi tekniğidir ${ }^{17}$.

CyberKnife, görüntü klavuzlu robotik radyocerrahi sistemidir. Hedef lezyonun etrafında hızlı doz düşüşü ile uyumlu radyasyon doz dağılımları sağlayabilen yüksek hassasiyette çapraz ateşlemeli radyasyon 1şınları verir. Aynı zamanda doğru hedef konumu için gerçek zamanlı görüntüleme ve doğru doz dağılımını sağlamak için yüksek hızlı robotik kullanır ${ }^{18}$. CK radyocerrahisi ve ekstrakranial olarak iyi ve kötü huylu durumları tedavi etmek amaciyla invaziv olmayan bir yöntem olarak çok daha fazla kullanılmaya devam etmektedir ${ }^{19}$.

$\mathrm{Bu}$ çalışmada daha önce RT almış erken evre meme kanseri tanıl1 10 hastanın bilgisayarlı tomografi (BT) görüntüleri üzerinde; APBI uygulaması ile iki farkl tedavi planlama tekniğinde sanal planlar oluşturularak dozimetrik açıdan karşılaştırılması amaçlanmıştır.

\section{Gereç ve Yöntem}

\section{Hasta Seçimi ve Görüntülerin Elde Edilmesi}

Bursa Uludağ Üniversitesi Tip Fakültesi Radyasyon Onkolojisi Anabilim Dalı'nda RT ile tedavi edilmiş 10 erken evre meme kanseri tanılı, lezyon çapı $3 \mathrm{~cm}$ ve altı olan hastalar seçildi. Hastalar seçilirken klip olmasına dikkat edildi. Çünkü klinik uygulamalarda görünür poş ve klipler GTV'nin izlenimini kolaylaştırmaktadır. Hastaların lezyonlarının 5 tanesi sağ, 5 tanesi ise sol yerleşimliydi. Lezyonların ortalama çapı 2,67 (2,0$3,0) \mathrm{cm}$ 'dir. Yapılan planlardaki GTV hacmi ortalama $59,286(42,48-86,61) \mathrm{cm}^{3}$ 'tür. Hastaların BT ile elde edilen üç boyutlu rekonstrüksiyon kesit görüntüleri tedavi planları oluşturulmak üzere, dijital ortam (Digital Imaging and Communications in Medicine, DICOM) aracılığı ile Accuray Precision ve Monaco 5.1 Tedavi Planlama Sistemi'ne gönderildi. Hastalara ait karakteristik bilgiler Tablo I'de verilmiştir.

Tablo I. Lezyonun çapını, GTV hacmini ve yerleşimini gösteren veriler

\begin{tabular}{|c|c|c|c|}
\hline Olgular & Lezyon Çapı (cm) & GTV Hacmi $\left(\mathbf{c m}^{3}\right)$ & Yerleşim \\
\hline 1.olgu & 2,9 & 42,48 & Sağ \\
\hline 2.olgu & 2,9 & 49,44 & Sol \\
\hline 3.olgu & 3,0 & 84,05 & Sol \\
\hline 4.olgu & 2,8 & 51,99 & Sağ \\
\hline 5.olgu & 2,6 & 47,97 & Sol \\
\hline 6.olgu & 2,6 & 63,43 & Sağ \\
\hline 7.olgu & 2,0 & 43,60 & Sol \\
\hline 8.olgu & 3,0 & 70,07 & Sağ \\
\hline 9.olgu & 2,2 & 53,22 & Sağ \\
\hline 10.olgu & 2,7 & 86,61 & Sol \\
\hline
\end{tabular}

GTV: görünür hedef hacim

$\mathrm{cm}$ : santimetre

\section{Tedavi Planlamasl}

Hastaların mevcut BT görüntüleri üzerinde Radyasyon Onkoloğu tarafindan RTOG (Radiation Therapy Oncology Group) protokollerine uygun görünür hedef volüm (GTV), planlanan hedef volüm (PTV) ve kritik organların (kalp, sağ-sol akciğer, aynı taraf meme ve karşı meme) konturlamaları yapıldı. Konturlama yap1lırken $\mathrm{PTV}=\mathrm{GTV}+15 \mathrm{~mm}$ marj verilerek ve riskli organlar ile ciltten $2 \mathrm{~mm}$ marj ile çıkarılarak konturlandı. Aynı zamanda hedef takibi için konulan klipler GTV marjı üzerinde olduğu için reçetelendirilen doz GTV'ye verilerek sanal planlar oluşturuldu. Tüm hastalar için günlük fraksiyon dozu 6 Gy ve toplam doz 30 Gy olacak şekilde sanal planları oluşturuldu. Tüm planlar için GTV'nin en az \%98'inin, reçete edilen dozun en az \%95'ini alması amaçlandı. Tüm planlar için "NSABP-B39/RTOG 0413, 3B-KRT" tolerans dozları dikkate alındı (Tablo II).

Tablo II. NSABP-39/RTOG 0413, 3D-CRT protokolüne dayalı normal doku için doz sinırlamalar1

\begin{tabular}{|l|l|l|}
\hline \multicolumn{1}{|c|}{ NSABP/RTOG } & \multicolumn{1}{c|}{ (3B-KRT) kısıtlama } & \multicolumn{1}{|c|}{$\begin{array}{c}\text { CyberKnife tedavi } \\
\text { (ortalama, oran) }\end{array}$} \\
\hline Aynı taraf meme & V30<35\% & Volüm: $8-13 \%$ \\
V15<60\% & Volüm: $16-30 \%$ \\
\hline Karşı meme & Dmax<1Gy & Max. doz: $1-2 G y$ \\
\hline Aynı taraf akciğer & V9<15\% & Volüm: $0-10 \%$ \\
\hline Karşı akciğer & V1.5<15\% & Volüm: $2-10 \%$ \\
\hline Kalp (sağ meme) & V1.5<5\% & NA \\
\hline Kalp (sol meme) & V1.5<40\% & Volüm: $25-54 \%$ \\
\hline
\end{tabular}

$\mathrm{V}_{1.5,9,15,30}: \% 1.5,5,9,15,30$ 'luk hacmin Gy cinsinden aldığ 1 doz değerleri

$\mathrm{D}_{\max }$ : Gy cinsinden maksimum doz değeri

Max doz: Gy cinsinden maksimum doz değeri

NA: doz değeri yok

3B-KRT: 3 Boyutlu Konformal Radyoterapi

NSABP/RTOG: National Surgical Adjuvant Breast and Bowel Project/Radiation Therapy Oncology Group (Ulusal Cerrahi Adjuvan Meme ve Bağırsak Projesi/Radyasyon Tedavisi Onkoloji Gru$\mathrm{bu})$

\section{VMAT Tedavi Planlamasi}

Monaco 5.1 tedavi planlama sisteminde yapılan planlarda çift ark planı yapılmıştır. Birinci ark için gantri açısı $330^{\circ}-60^{\circ}$ ve ikinci ark için $180^{\circ}-70^{\circ}$ açıları verilerek yapılmıştır. "Monte Carlo" hesaplama algoritmasında minimum segment genişliği 0,3 ve istatistiksel belirsizliği 0,5 olarak belirlenmiştir. $6 \mathrm{MV}$ foton enerji kullanılarak planlar oluşturuldu. Optimizasyon sayfasında hedef ve volüm için uygun minimum, maksimum tedavi dozu, riskli organlar için "NASPB/RTOG Protokolünde" belirtilen normal doku dozu kısitlamaları uyguland. 


\section{CyberKnife Tedavi Planlaması}

Accuray Precision tedavi planlama sisteminde planlar X-Sight Akciğer İzleme Algoritması kullanılarak sanal tedavi planları oluşturuldu. Planlarda X-Sight Akciğer İzleme Algoritmasını kullanabilmek için ilk olarak X-Sight Vertebra İzleme Algoritmasında Spine Tracking tanıtıldı. Bu işlemden sonra X-Sight Akciğer İzleme Algoritması yeniden seçildi ve meshler ayarland1. Plan menüsünden tedavi parametreleri olan 5 fraksiyonda 30 Gy değerleri girilmiştir. Planlama sisteminin bir özelliği olan Beam Intersection (Işın Kesişimi) özelliği ile VOI'ler listesini ve 1şın kesişsimi için seçenekleri ayarland. Yapılan her planda karşı meme için ışın kesişimi 'never' (1şınların kesişmesine izin vermez) seçildi. Sol meme yerleşimli lezyon bulunan planlarda ise kalp için 1şın kesişimi 'never' olarak ayarlandı. Daha sonra planların gerçekleştirildiği VOLO sistemi seçildi. Target Goals sekmesinden GTV'nin minimum ve maksimum değerleri girildikten sonra tümör etrafına kabuklar (Shell) oluşturuldu $(2,5,10,15) \mathrm{mm}$. Kabuklar oluşturulurken kritik organlara yakın bölgelerden olabildiğince kaçınıldı. Sonrasında Critical Goals kısmına kritik organların en az dozu almalarını sağlamak için sınırlamalar yapıldı. Planlar yapılırken GTV'nin en az \%98'inin reçete edilen dozun en az \%95'ini almasına ve kritik organların alabilecekleri en az dozu almalarına dikkat edildi. Çalışmada Monte Carlo Algoritması kullanıldı. Maksimum kontrol noktas 1se 100 olarak belirlendi.

\section{Istatistiksel Analiz}

Çalışmada 10 erken evre meme kanserli olgunun 2 farklı planlama sisteminde yapılan sanal planları istatistiksel olarak karşılaştırılırken tüm analizlerde SPSS programı kullanılmıştır. Bunun için yapılan planların $\mathrm{D}_{\max }$ (cGy), $\mathrm{D}_{\min }$ (cGy), V (\%95), HI, CI gibi verilerin karşılaştırılmasında ölçüm verilerinin normal dağılım gösterip göstermediğine bakıldı. Anlamlılık değeri $\mathrm{p}$ değeri 0,05 'ten büyük ise normal dağılım, büyük değilse normal olmayan dağılım göstermektedir. Normal dağılım gösteren verilerde 'Independent Samples-T' testi, normal dağılım göstermeyen verilerde ise 'Mann Whitney $U$ ' testi kullanılmıştır. Veriler normal dağılıma uygun ise sonuçlar; "Ortalama \pm Standart Sapma" ve veriler normal dağılıma uygun değilse; "Ortanca (Minimum-Maksimum)" olarak verildi. İstatistik sonucunda belirlenen $\mathrm{p}$ değeri 0,05 'ten küçük olduğunda istatistiksel olarak anlamlı bir farklılık olduğunu belirtmektedir.

\section{Bulgular}

Tedavi teknikleri arasında GTV'nin $D_{\max }(p=0,002)$ değerleri açısından VMAT tekniğinde anlamlı bir fark bulundu. HI $(p<0,001)$ ve CI $(p<0,001)$ değerlerine bakıldığında tüm tekniklerin ICRU kriterlerine uygun olduğu ve HI ile CI için VMAT tekniğinin daha iyi sonuç verdiği görülmüştür. Tedavi teknikleri arasında tedavi süresi $(s)(p<0,001)$ değerlerine bakıldığında VMAT tekniğinin lehine anlamlı bir fark bulunmuş ve daha iyi olduğu görülmüştür (Tablo III).

Tablo III. İki teknikte GTV dozları cGy cinsinden olmak üzere, HI ve CI için elde edilen istatistiksel veriler

\begin{tabular}{|l|l|l|l|}
\hline & \multicolumn{1}{|c|}{ VMAT } & \multicolumn{1}{c|}{ CYBERKNIFE } & p değeri \\
\hline GVT & \multicolumn{3}{|c|}{} \\
\hline $\mathbf{D}_{\max }$ (cGy) & $3323(3266-3359)$ & $3571,5(3033-3703)$ & 0,002 \\
\hline $\mathbf{V}_{95}(\mathbf{c G y})$ & $3092,5(3073-3166)$ & $3001,5(2999-3002)$ & $<0,001$ \\
\hline $\mathbf{V}_{98}(\mathbf{c G y})$ & $3074,5(3063-3141)$ & $2941,5(2491-2954)$ & $<0,001$ \\
\hline $\mathbf{H I}$ & $1,04(1,04-1,05)$ & $1,21(1,16-1,25)$ & $<0,001$ \\
\hline $\mathbf{C l}$ & $0,57 \pm 0,03$ & $1,113 \pm 0,02$ & $<0,001$ \\
\hline SÜRE (s) & $157,48 \pm 7,73$ & $1536 \pm 117,30$ & $<0,001$ \\
\hline
\end{tabular}

$\mathrm{D}_{\max }$ : cGy cinsinden maksimum doz değeri

$\mathrm{V}_{95,98}$ : 95,98'lik hacmin cGy cinsinden aldığı doz değeri

HI: homojenite indeksi

CI: konformite indeksi

s: saniye

Karş1 akciğerin $D_{\max }(p=0,436)$ ve $V_{1.5}(p=0,684)$ değerlerine bakıldığında her iki tedavi tekniği açısından anlamlı fark bulunmadı; ancak $\mathrm{D}_{\max }$ değerlerine 88 (53-262) bakıldığında VMAT tedavi tekniğinin daha üstün olduğu görüldü. $V_{1.5}$ değerleri için $0,2(0-2,7)$ CyberKnife tekniğinin daha üstün olduğu görüldü (Tablo IV).

Tablo IV. İki teknikte kritik organ dozları ve istatistiksel veriler

\begin{tabular}{|c|c|c|c|}
\hline & VMAT & CYBERKNIFE & p değeri \\
\hline \multicolumn{4}{|c|}{ Karşı Akciğer } \\
\hline$D_{\max }(c G y)$ & $88(53-262)$ & $136,5(28-265)$ & 0,436 \\
\hline $\mathrm{V}_{1.5}$ (cGy) & $0,855(0-1,58)$ & $0,2(0-2,7)$ & 0,684 \\
\hline \multicolumn{4}{|c|}{ Aynı Taraf Akciğer } \\
\hline$D_{\max }(c G y)$ & $2130 \pm 361,47$ & $1778 \pm 314,47$ & 0,032 \\
\hline $\mathrm{V}_{9}(\%)$ & $2,13 \pm 1,30$ & $4,26 \pm 2,80$ & 0,049 \\
\hline \multicolumn{4}{|c|}{ Karşı Meme } \\
\hline$D_{\max }(c G y)$ & $36,5(13-158)$ & $19,5(0-37)$ & 0,218 \\
\hline \multicolumn{4}{|c|}{ Aynı Taraf Meme } \\
\hline $\mathrm{V}_{30}(\%)$ & $9,99 \pm 3,38$ & $6,06 \pm 2,42$ & 0,013 \\
\hline $\mathrm{V}_{15}(\%)$ & $26,96 \pm 6,39$ & $18,36 \pm 6,20$ & 0,007 \\
\hline \multicolumn{4}{|c|}{ Kalp (Sağ Meme) } \\
\hline$D_{\max }(c G y)$ & $14,02 \pm 70,25$ & $93,2 \pm 58,05$ & 0,282 \\
\hline $\mathrm{V}_{1.5}(\%)$ & $0,11(0-0,46)$ & $0,005(0-0,01)$ & 0,548 \\
\hline \multicolumn{4}{|c|}{ Kalp (Sol Meme) } \\
\hline$D_{\max }(c G y)$ & 406 (220-758) & $193(103-708)$ & 0,095 \\
\hline $\mathrm{V}_{1.5}(\%)$ & $5,23(1,68-15,55)$ & $0(0-0)$ & 0,008 \\
\hline
\end{tabular}

$\mathrm{D}_{\max }$ : cGy cinsinden maksimum doz değeri

$\mathrm{V}_{1,5}$ : \%1,5'lik hacmin cGy cinsinden aldığ

$\mathrm{V}_{1.5,9,15,30}: 1.5,9,15,30$ Gy'lik dozu alan volümü 


\section{Erken Evre Meme Kanserinde CyberKnife}

Aynı taraf akciğerin $\mathrm{D}_{\max }(\mathrm{p}=0,032)$ değerlerine bakıldığında CyberKnife tedavi tekniği lehine anlamlı fark bulunurken; $\mathrm{V}_{9}(\mathrm{p}=0,049)$ değerleri için ise VMAT tedavi tekniği lehine anlamlı fark bulundu (Tablo IV).

Karşı memenin $D_{\max }(p=0,218)$ değerlerine bakıld1ğında iki tedavi tekniği açısından da anlamlı fark görülmedi. Aynı taraf memenin $\mathrm{V}_{30}(\mathrm{p}=0,013)$ ve $\mathrm{V}_{15}$ $(p=0,007)$ değerlerine bakıldığında CyberKnife tedavi tekniği lehine anlamlı fark bulunmuş ve değerler karşılaştırıldığında CyberKnife tedavi tekniğinin VMAT tedavi tekniğine göre daha az doz aldığı saptand (Tablo IV).

Sağ meme yerleşimli lezyon için kalbin $D_{\max }$ $(p=0,282)$ ve $V_{1.5}(p=0,548)$ değerlerine bakıldı ̆ğnda iki tedavi tekniği açısından anlamlı fark bulunmad (Tablo IV). Sol meme yerleşimli tümör için kalbin $\mathrm{D}_{\max }(\mathrm{p}=0,095)$ değerlerine bakıldığında iki tedavi tekniği açısından anlamlı fark olmadığı görülürken; $\mathrm{V}_{1.5}(\mathrm{p}=0,008)$ değerlerine bakıldığında CyberKnife tedavi tekniği lehine anlamlı fark olduğu görüldü (Tablo IV).

\section{Tartışma ve Sonuç}

Sağ kalım oranı yüksek erken evre meme kanserli hastalarda RT uygulaması uzun yıllardır standart tedavi haline gelmiştir. RT ile sağ kalım ve lokal kontrol oranları oldukça artmıştır. Erken evre meme kanserinde APBI, tüm meme ıșınlamasının aksine yalnızca rezeksiyon hacmine daha kısa fraksiyonda daha düşük total doz ve daha yüksek fraksiyon doz şeması uygulayarak tedavi süresini azaltmayı sağlar. Lokal yinelemelerin en sık tümör yatağı ve çevresinde görülmesi sebebi ile APBI uygulaması yapılmaktadır. Günümüzde RT tekniklerindeki gelişmeler ve yeni deneyimler, meme kanseri tedavisinde de alışılmış tekniklere alternatif tedavi seçenekleri sunmaktadır. CyberKnife, yakın zamanda APBI için olası bir alternatif tedavi tekniği olarak değerlendirilmektedir.

Çalışmamızda APBI deneyimi için VMAT ve CyberKnife tedavi planlama teknikleri ile sanal planlar yapılarak dozimetrik olarak karşılaştırılmıștır.

Meme kanserinde kalp oldukça risk taşıyan bir organdır. Kalbin gereksiz doz almasını önlemek, geç kardiyak yan etkilerin azalması açısından oldukça önemlidir. Çalışmamızda săg meme yerleşimli lezyon olan hastalarda kalbin aldığı doz açısından iki planlama tekniği arasında anlamlı fark bulunmadı. Sol meme yerleşimli lezyon olan hastalarda kalbin 1,5 Gy doz alan hacminin CK tedavi tekniğinde daha iyi sonuçlar verdiği görüldü. Kaydedilen değerlere bakıldığında \%0 (0-0) değerler VMAT tedavi tekniğine göre fazlasıyla düşüktü. Lee ve ark., (2018) çalışmalarında 10 hasta için 5 fraksiyonda totalde 30 Gy'lik doz şemasını kullanmış ve APBI'yı CK için değerlendirmişlerdir. Sonuçlarını VMAT tedavi planlama sistemi sonuçları ile karşılaştırmışlardır. Çalışma sonucunda yapılan analizler kalbin 1,5 Gy doz alan hacminin CK tedavi planlama sisteminde $\% 23$ (4-36), VMAT tedavi planlama sisteminde ise \%43 (28-59) şeklindedir. Ayrıca, 5 Gy'den daha az doz alan kalp hacminde de önemli farklılıklar gözlendiği sonuçlara aktarılmıştır ${ }^{20}$. Lee ve ark., (2018) çalışması ile çalışmamızın sonuçları oldukça benzerlik göstermektedir fakat bizim çalışmamızda kalp için ışın kesişimi özelliğinin kullanılması ve lezyonun yerleşim yeri kaydedilen doz değerlerini oldukça etkiledi ve düşük tuttu.

Vermeulen ve ark., (2011) yılında 10 hasta için yaptıkları çalışmada 5 fraksiyonda 30 Gy doz reçetelendirerek APBI için $\mathrm{CK}$ ve 3D-CRT tedavi tekniklerini karşılaştırmışlardır. Çalışma sonucunda 3B-KRT tedavi tekniği sonucunda kalbin 1,5 Gy doz alan hacmi iki hastada \%19, ve \%6 hesaplanmıs ve diğer hastalar için sonuçların \%5'ten küçük olduğu kaydedilmiştir. CK tedavi planlama sisteminde ise sağ meme hastalarının kalbin 1,5 Gy doz alan hacminin NA olduğu kaydedilmiştir ${ }^{21}$. Sonuçlara bakıldığında bizim çalışmamızdaki sonuçlar da NA değerindedir. Çalışmamızda VMAT tedavi tekniğinde kaydettiğimiz en düşük volüm sonuçlarımız ise \%1,68 (0,114- 0,20) şeklindedir. Vermeulen ve ark., (2011) çalışması ile çalışmamız karşılaştırıldığında CK tedavi planlama sisteminde kaydedilen değerler hemen hemen aynı ve diğer tekniklere oranla çok daha düşüktür. Sağ meme yerleşimli lezyon bulunan olgularda kalbin aldığ dozlar değerlendirildiğinde APBI uygulamasında CK tedavi tekniğinin anlamlı bir yaklaşım olarak değerlendirilebilir.

Sol meme yerleşimli olgularda anatomik yakınlıktan dolayı ortalama kalp dozu yüksektir tedavide kalbin aldığı dozlara, özellikle riskli hastalarda ve uzun sağ kalım beklenen hastalarda dikkat etmek gerekir. Sol meme yerleşimli lezyon olan hastalarda kalp için CK tedavi tekniğinde kaydedilen ortalama kalp dozu 271,8 cGy iken VMAT tekniğinde 457,8 cGy'dir. Benzer bir çalışma ile Taylor ve ark., (2015) 10 yıllık analizlerinde, sol ve sağ meme radyoterapisi uygulanan hastalarda ortalama kalp dozu anlamlı olarak farklı bulunmuştur (5,6-3,3 Gy). Ayrıca mammaria bölgesi lenf nodlarına radyoterapi uygulanan olgularda da ortalama kalp dozunun daha yüksek olduğu saptanmıştır ${ }^{4}$. Ortalama kalp dozunun oldukça önemli bir kriter olduğu bildirilmektedir. Ortalama kalp dozunu düşürebilmek için tercih edilen RT tekniğinin oldukça iyi değerlendirilmesi gerekir. Bizim çalışmamızda tedavi teknikleri arasında $\mathrm{CK}$ tedavi tekniğinin ortalama kalp dozu için daha düşük değerler sağladığ 1 görülmektedir.

Meme kanseri Radyoterapisinde anatomik yakınlıktan dolayı oluşabilecek pulmoner geç yan etkilerin engellenmesi veya azaltılması için akciğer dozunun gerekli doz kısıtlamalarını aşmamasına dikkat edilmelidir. Çalışmamızda karşı akciğerin 1,5 Gy doz alan volümü 
CK tedavi tekniğinde $\% 0,2(0-2,7)$, VMAT tedavi tekniğinde ise \%0,855 $(0-1,58)$ olarak kaydedilmiştir. CK tedavi tekniği VMAT tedavi tekniğine göre daha üstün bulunmuştur. Vermeulen ve ark., (2011), 1,5 Gy doz alan karşı akciğer volümünün 3D-CRT için $<\% 15$ olarak, CK için ise volümün \%2-10 aralığında olması$\mathrm{n}$ istemişlerdir. Yapılan analizler sonucunda 3B-KRT için bir hastanın 1,7 Gy doz alan karşı akciğer volümü \%19 olarak hesaplanmıştır (NSABP kılavuzları $<\% 15$ ). CK tedavi planlama sisteminden elde edilen sonuçların ise çok daha düşük (\%6) olduğu sonucuna varılmıştır ${ }^{21}$. Sonuç olarak karşı akciğer için CK-APBI uygulaması sonuçları her iki çalışma için de daha ilham vericidir.

Çalışmamızda aynı taraf akciğerin 9 Gy alan volümleri değerlendirildiğinde, $\mathrm{CK}$ tedavi tekniğinde ortalama $4,26 \pm 2,80$ olarak, VMAT tedavi tekniğinde ise $2,13 \pm 1,30$ olduğu görülmüsstür. Varılan sonuçlar VMAT tedavi tekniğinin aynı taraf akciğer için uygun tedavi tekniği olduğunu gösterse de CK tedavi tekniğinden elde edilen sonuçlarda akciğer için oldukça düşük değerlerdir. Çalışmamızı destekleyecek bir başka çalışma, Vermeulen ve ark., (2011) çalışmasında aynı taraf akciğerin 9 Gy doz alan volümleri 3BKRT için $<\% 15$ olarak kaydedilmiştir. CK için volüm aralığı $(\% 0-10)$ olarak kaydedilmiş ortalama değer $\% 5$ olarak elde edilmiştir ${ }^{21}$. Çalışmalar değerlendirildiğinde CK tedavi planlama sisteminin aynı taraf akciğer için düşük dozlara ulaştı̆̆ görülmüştür. Goggin ve ark (2015) 9 hasta için 5 fraksiyonda totalde 30 Gy doz reçetelendirmiş ve çalışmalarını 3B-KRT-CK için yapmışlardır. Çalışmalarında aynı taraf akciğer için doz kısıtlamalarını şu şekilde belirlemişlerdir; reçete edilen dozun \%30'unu ve \%5'ini alan ayn taraf akciğer hacmi \%15'ten düşük olmalıdır. Sonuçlar değerlendirildiğinde $\left(\mathrm{V}_{30 \%}<15 \%, \mathrm{~V}_{5 \%}<15 \%\right) 3 \mathrm{D}$-CRT için veriler sırasıyla $0,7(0-1,8)$ ve $6,2(2,8-11,8)$, CK için veriler sirasiyla $1,6(0,0-6,6)$ ve $17,9(4-45)$ olarak kaydedilmiştir ${ }^{22}$. Akciğer için belirlenen doz kısıtlamalarının 3B-KRT tedavi tekniğinde daha iyi olduğu görülmüştür; ancak CK tedavi tekniğinde edilen değerler de belirlenen doz kısıtlamalarını kayda değer seviyede aşmamış ve yakın gözlenmiştir. Yapılan çalışmalar aynı taraf akciğer için CK-APBI uygulamasında düşük doz değerlerine ulaşılabileceğini desteklemektedir.

Çalı̧̧mamızda karşı memenin $\mathrm{D}_{\max }$ (cGy) doz değerleri CK tedavi tekniğinde $19,5(0-37)$, VMAT tedavi tekniğinde 36,5 (13-158) olarak kaydedilmiştir. Doz sınırlamalarımız VMAT tedavi tekniği için $\mathrm{D}_{\max }<1$ Gy, CK tedavi tekniği için maksimum doz 1-2 Gy olarak belirlendi ve CK tedavi tekniğinde kaydedilen sonuçların daha düşük olduğu görüldü. Planlama esnasında CK tedavi tekniğinin bir özelliği olan Beam Intersection (1şın kesişimi) ile karşı memeden 1şın kesişimi engellendi ve karşı memenin alacağ 1 dozlar düşürüldü. $\mathrm{Bu}$ deneyim sayesinde $\mathrm{CK}$ tedavi tekniğin- de riskli organların gereksiz doz almasını engellemek oldukça başarılı bir yaklaşımdır. Lozza ve ark., (2018) yılında 20 hasta için yaptıkları çalışmada, karşı memenin $\mathrm{D}_{\max }(\mathrm{Gy})$ dozunun reçete edilen dozun $<\% 3$ olmasını planlamışlardır. Karşı meme $\mathrm{D}_{100 \%}(\mathrm{~Gy})$ medyan $0,09(0,03-0,12)$ olarak kaydedilmiştir. Medyan meme $\mathrm{V}_{100}$ ve $\mathrm{V}_{50}$ sirasiyla 0,6 (aralık:0-13) ve 18,6 (aralık:7,5-37)'dır. Lozza ve ark., (2018) çalışmalarında Iris kolimatörünü kullanmışlardır ${ }^{23}$. Bizim çalışmamız ile kullanılan kolimatör farkı olmasına rağmen kaydedilen sonuçlar oldukça düşüktür. Lee ve ark., (2018) yılında CK-APBI değerlendirdikleri çaıı̧̧mada doz sınırlamalarını karşı meme için $\mathrm{D}_{\max }<1$ Gy olarak belirlemişlerdir. Karşı meme için CK tedavi planlama sisteminde $\mathrm{D}_{\max }$ dozu 3 Gy olarak kaydedilmiş ve bütün hastalar için maksimum aralık (1-8 Gy) olarak belirlenmiştir. Yaptıkları çalışmayı VMAT tedavi planlama sistemi ile karşılaştırmış ve $\mathrm{D}_{\max }$ doz aralığını (2-5 Gy) kaydetmişlerdir. CK tedavi planlama sisteminde kaydedilen değerler VMAT tedavi planlama sistemine göre oldukça düşük sonuçlardır. "CK tedavi planlama sisteminde "1̧̧ın kesişimi" tümör veya $O A R$ ile keyfi olarak sınırlama işlevine sahiptir. Bu işlev, hedef kapsamı azaltmadan iyi kullanılırsa, karşı memenin maksimum dozlarını kontrol etmek mümkün olabilir" ${ }^{20}$. Bu tür çalışmalar CK-APBI deneyimlerinde farklı gelişmelere ışık tutacaktır.

Çalışmamızda aynı taraf memenin $30 \mathrm{~Gy}$ doz alan hacmi CK tedavi tekniğinde minimum \%2,9, maksimum $\% 9,8$ olarak, VMAT tedavi tekniğinde minimum $\% 4,49$, maksimum $\% 16,06$ olarak kaydedilmiştir. VMAT tedavi tekniğinde doz sinırlaması $\mathrm{V}_{30}<35 \%$, CK tedavi tekniğinde $\mathrm{V}_{30}=(8-13 \%)$ olarak belirlenmiştir. 15 Gy doz alan hacmi CK tedavi tekniğinde minimum $\% 9,4$, maksimum $\% 27,9$, VMAT tedavi tekniğinde ise minimum $\% 15,46$, maksimum $\% 35,40$ olduğu görülmüştür. Doz sinırlamaları VMAT tedavi tekniğinde $\mathrm{V}_{15}<60 \%$, CK tedavi tekniğinde $\mathrm{V}_{15}=$ (16$30 \%$ ) olarak belirlenmiştir. Tedavi teknikleri açısından CK tedavi tekniğinde kaydedilen sonuçların daha düşük olduğu görülmüştür. Lee ve ark., (2018) yaptıkları çalışmalarında aynı taraf meme için doz sınırlamalar1 NSABP-39/RTOG 0413, 3B-KRT protokolüne göre belirlemişlerdir. Lee ve ark., (2018) çalışma sonuçlarına göre CK tedavi planlama sisteminde aynı taraf memenin 30 Gy alan hacmi maksimum \%22, minimum $\% 2$ olarak kaydedilmiş, 15 Gy alan hacmi maksimum $\% 48$, minimum hacim ise $\% 5$ olarak kaydedilmiş ve bu değerler VMAT tedavi planlama sistemi ile karşılaştırılmış̧ır. VMAT tedavi planlama sisteminde ayn taraf memenin $30 \mathrm{~Gy}$ alan hacmi \%12 (2-25) olarak, 15 Gy alan hacmi \%25 (5-57) olarak kaydedilmiştir ${ }^{20}$. Çalışmamız ile sonuçları oldukça yakın değerler vermiş̧tir.

Goggin ve ark (2015) 9 hasta için 5 fraksiyonda totalde 30 Gy doz reçetelendirmiş ve çalışmalarını 3DCRT-CK için yapmışlardır. Çalışmalarında aynı taraf 


\section{Erken Evre Meme Kanserinde CyberKnife}

meme için doz kısıtlamaları şu şekilde belirlenmiştir; reçete edilen dozun \%100'ünü alan meme hacmi \%35'ten az, \%50'sini alan meme hacmi \%60'tan az olmalıdır. Sonuçlar değerlendirildiğinde 3B-KRT için elde edilen veriler; $\left(\mathrm{V}_{100 \%}<35 \%\right)$ için 15,3 (7$25,3)$ ve $(\mathrm{V} 50 \%<60 \%)$ için $37,5(22,9-50,3)$ olarak kaydedilmiştir. CK tedavi tekniği için sonuçlar sırasiyla, $12,2(7,3-23,1)$ ve $24,2(15,5-37,8)$ olarak kaydedilmiştir. Goggin ve ark (2015) çalışmalarında CK tedavi tekniğinde yapılan planlarda $M L C$ kolimatör ve FSPB (finite-sized pencil beam) algoritmasını kullanmışlardır ${ }^{22}$. İki farklı tedavi tekniği karşılaştırıldığında CK tedavi tekniğinden elde edilen sonuçların daha düşük olduğu ve belirlenen doz kısıtlamalarına daha uygun değerler olduğu anlaşılmaktadır. Goggin ve ark (2015) çalışması ile bizim çalışmamızdaki değerlerin çok az farklılık göstermesinin kullanılan algoritma frakından dolayı olduğunu düşünmekteyiz. Sonuçlar değerlendirildiğinde $\mathrm{CK}$ tedavi planlama sistemindeki veriler aynı taraf meme için CK-APBI deneyiminin uygunluğunu savunur şekildedir.

Sonuç olarak; erken evre meme kanserli olgularda karşı meme, akciğer ve kalp gibi kritik organların fonksiyonel olarak korunabilmesi, sağ kalımı olumsuz etkileyebilecek yan etkilerin önlenmesi açısından önemlidir. Çalışmamızda sanal planlarımızın; sağlıklı meme, kalp ve diğer kritik organların korunması açısından CyberKnife tekniğinin, VMAT tedavi tekniğine göre daha iyi dozimetrik sonuçlar verdiği anlaşılmıştır. Bu sebeple; lezyon boyutu ve yerleşimine bağl olarak CyberKnife tekniğinde, kritik organları 1şınlanan alandan çıkarabilmek için kullandığımız Beam Intersection (1şın kesişimi) özelliğinin sağladığı düşük dozlardan dolayı CK-APBI uygulamasının kardiyak riskli ve uygun olgularda tercih edilebilir olduğunu düşünmekteyiz.

Etik Kurul Onay Bilgisi:

Onaylayan Kurul: Uludağ Üniversitesi Tıp Fakültesi Klinik Araştırmalar Etik Kurulu 2011-KAEK-26

Onay Tarihi: 22 Eylül 2021

Karar No: 2021-13/17

Araştırmacı Katkı Beyanı: Fikir ve tasarım: S.K.Ç., H.M.K.; Veri toplama ve işleme: H.M.K.; Analiz ve verilerin yorumlanması:

H.M.K., S.K.Ç., S.G.T.; Makalenin önemli bölümlerinin yazılması: H.M.K., S.K.C..

Destek ve Teşekkür Beyanı:

Bu makalede yer alan çalışmalarda herhangi bir kurum tarafindan finansal destek sağlanmamıştır.

Çıkar Çatışması Beyanı:

Bu makalede makale yazarlarının çıkar çatışması beyanı yoktur.

\section{Kaynaklar}

1. Aksoy, Y. E., Ceber Turfan, E., Sert, E., ve Mermer, G. Barriers on Breast Cancer Early Detection Methods. Türkiye Meme Hastalıkları Dernekleri Federasyonu., The Journal of Breast Health. (2015);11(1), 26-30.
2. Kurt, H., Keskek, S. O., Çil, T., ve Canataroğlu, A. Complementary/alternative therapies in patients with breast cancer. Turk Onkoloji Dergisi. Adana. (2013);28(1), 10-15.

3. Whelan, T. J., Olivotto, I. A., Parulekar, W. R., Ackerman, I., Chua, B. H., et al. Regional Nodal Irradiation in Early-Stage Breast Cancer. New England Journal of Medicine. (2015);373(4), 307-316.

4. Taylor, C. W., \& Kirby, A. M. Cardiac Side-effects From Breast Cancer Radiotherapy. Clinical Oncology. (2015);27(11), 621-629.

5. Agrawal, R. K., Aird, E. G. A., Barrett, J. M., Barrett-Lee, P. J., Bentzen, S. M., et al. The UK Standardisation of Breast Radiotherapy (START) Trial B of radiotherapy hypofractionation for treatment of early breast cancer: a randomised trial. The Lancet. (2008); 371(9618), 1098-1107.

6. Rault, E., Lacornerie, T., Dang, H. P., Crop, F., Lartigau, E., et al. Accelerated partial breast irradiation using robotic radiotherapy: A dosimetric comparison with tomotherapy and threedimensional conformal radiotherapy. Radiation Oncology. (2016);11(1), 1-8.

7. Njeh, C. F., Saunders, M. W., \& Langton, C. M. Accelerated Partial Breast Irradiation (APBI): A review of available techniques. Radiation Oncology. (2010);5(1), 1-28.

8. Cholewka, A., Szlag, M., Białas, B., Kellas-Śleczka, S., Ślosarek, K. The importance of the implant quality in APBI Gliwice experience. Dosimetric evaluation. Journal of Contemporary Brachytherapy. (2013);5(4), 227-231.

9. Li, X. A., Tai, A., Arthur, D. W., Buchholz, T. A., Macdonald, S., et al. Variability of Target and Normal Structure Delineation for Breast Cancer Radiotherapy: An RTOG Multi-Institutional and Multiobserver Study. International Journal of Radiation Oncology Biology Physics. (2009);73(3), 944-951.

10. B.C. John Choa,b, Coen W. Hurkmansa , Eugene M.F. Damena , Lambert J. Zijpa , Ben J. Mijnheer ., Intensity modulated versus non-intensity modulated radiotherapy in the treatment of the left breast and upper internal mammary lymph node chain: a comparative planning study. Radiotherapy and Oncology. (2002);62(3), 127-136

11. Soile Tapio. Pathology and biology of radiation-induced cardiac disease. Journal of Radiation Research, 2016; 57(5), 439448

12. Laxmi S. Mehta, MD, FAHA, Chair Karol E. Et al. Cardiovascular Disease and Breast Cancer: Where These Entities Intersect A Scientific Statement From the American Heart Association., American Heart Association. Circulation. 2018; 137(8), 30-66

13. Carolyn W. Taylor, DPhil, FRCR, Zhe Wang, et al. Exposure of the Heart in Breast Cancer Radiation Therapy: A Systematic Review of Heart Doses Published During 2003 to 2013. International Journal of Radiation Oncology*Biology*Physics. 2015;93(4), 845-853

14. K. Kikuchi (Koji), H. Koyama (Hideki), H. Masuda (H.), Y. Nomura (Y.), DS Sakai (Debbie), et al. Effects of radiotherapy and of differences in the extent of surgery for early breast cancer on local recurrence and 15-year survival: an overview of the randomised trials Early Breast Cancer Trialists' Collaborative Group (EBCTCG)., Lancet. 2005; 366(9503), 2087-2106

15. Benedict, S. H., Yenice, K. M., Followill, D., Galvin, J. M., Hinson, W., et al. Stereotactic body radiation therapy: The report of AAPM Task Group 101. Medical Physics. 2011;37(8), 4078-4101

16. R. Ciérvide Á. Montero · G. Potdevin J. García · M. G. Aranda · B. Álvarez et al. 5-year results of accelerated partial breast irradiation (APBI) with SBRT (stereotactic body radiation therapy) and exactrac adaptive gating (Novalis $®$ ) for very early breast cancer patients: was it all worth it. Clinical and Translational Oncology. (2021); 23:2358-2367 
H.M. Kılıç, ark.

17. Jamesl. Bedford,Ph.D.,Andalanp. Warrıngton, M.Sc Commissionıng Of Volumetric Modulated Arc Therapy (Vmat) International Journal of Radiation Oncology*Biology*Physics. 2009;73(2), 537-545

18. Gibbs, I. C. Frameless İmage-Guided İntracranial And Extracranial Radiosurgery Using The Cyberknifetm Robotic System. Cancer/Radiotherapie, (2006);10(5), 283-287.

19. Kurup, G. CyberKnife: A new paradigm in radiotherapy. Journal of Medical Physics. 2010; 35(2), 63-64

20. Lee, C. Y., Kim, W. C., Kim, H. J., Lee, J., Park, S., \& Huh, H. Do. Dosimetric Plan Comparison of Accelerated Partial Breast Irradiation (APBI) Using CyberKnife. Progress in Medical Physics. (2018);29(2), 73-80

21. Vermeulen, S., Cotrutz, C., Morris, A., Meier, R., Buchanan, C., et al. Accelerated partial breast irradiation: Using the CyberKnife as the radiation delivery platform in the treatment of early breast cancer. Frontiers in Oncology. 2011;1(NOV), 18

22. L. M. Goggin, PhD1, M. Descovich, PhD1, C. McGuinness, $\mathrm{PhD1}$, S. Shiao, MD, PhD1, J. Pouliot, PhD1, and C. Park, MD1. Dosimetric Comparison Between 3-Dimensional Conformal and Robotic SBRT Treatment Plans for Accelerated Partial Breast Radiotherapy. Technology in Cancer Research \& Treatment. 2016;15(3), 437-445

23. Lozza, L., Fariselli, L., Sandri, M., Rampa, M., Pinzi, V., et al. Partial breast irradiation with CyberKnife after breast conserving surgery: A pilot study in early breast cancer. Radiation Oncology. 2018;13(1), 1-11. 